\title{
Cyclooxygenase-2 inhibition restored endothelium-mediated relaxation in old obese Zucker rat mesenteric arteries
}

\section{Emilie Vessières ${ }^{1,2}$, Eric J. Belin de Chantemèle ${ }^{1,2}$, Bertrand Toutain ${ }^{1,2,3}$, Anne-Laure Guihot ${ }^{1,2}$, Alain Jardel ${ }^{3}$, Laurent Loufrani ${ }^{1}$ and Daniel Henrion ${ }^{1,2,4 *}$}

\author{
1 Centre National de la Recherche Scientifique UMR 6214, Université d'Angers, Angers, France \\ 2 Institut National de la Santé et de la Recherche U771, Université d'Angers, Angers, France \\ 3 Integrated Neurovascular Biology, University of Angers, Angers, France \\ 4 Centre Hospitalier Universitaire d'Angers, Angers, France
}

Edited by:

Michael A. Hill, University of Missouri, USA

\section{Reviewed by:}

Issy Laher, University of British

Columbia, Canada

Kim Dora, University of Oxford, UK

${ }^{*}$ Correspondence:

Daniel Henrion, Department of Integrated Neurovascular Biology, UMR CNRS 6214 - INSERM 771 , Faculté de Médecine, 49045 Angers, France.

e-mail:daniel.henrion@univ-angers.fr
Metabolic syndrome is associated with reduced endothelial vasodilator function. It is also associated with the induction of cyclooxygenase-2 (COX2), which produces vasoactive prostanoids. The frequency of metabolic syndrome increases with age and aging per se is a risk factor associated with reduced endothelium-mediated relaxation. Nevertheless, the combined effect of aging and metabolic syndrome on the endothelium is less known. We hypothesized that COX2 derived prostanoids may affect endothelium function in metabolic syndrome associated with aging. We used obese Zucker rats, a model of metabolic syndrome. First order mesenteric arteries were isolated from 4-and 12-month-old rats and acetylcholine (endothelium)-dependent relaxation determined using wire-myography. Endothelium-mediated relaxation, impaired in young Zucker rats (89 versus $77 \%$ maximal relaxation; lean versus Zucker), was further reduced in old Zucker rats (72 versus $51 \%$, lean versus Zucker). The effect of the nitric oxide-synthesis inhibitor L-NAME on the relaxation was reduced in both young and old Zucker rats without change in eNOS expression level. COX inhibition (indomethacin) improved acetylcholine-mediated relaxation in old obese rats only, suggesting involvement of vasoconstrictor prostanoids. In addition, COX2 inhibition (NS398) and TxA2/PGH2 receptor blockade (SQ29548) both improved relaxation in old Zucker rat arteries. Old Zucker rats had the highest TxB2 (TxA2 metabolite) blood level associated with increased COX2 immunostaining. Chronic COX2 blockade (Celecoxib, 3 weeks) restored endothelium-dependent relaxation in old Zucker rats to the level observed in old lean rats. Thus the combination of aging and metabolic syndrome further impairs endothelium-dependent relaxation by inducing an excessive production of COX2-derived vasoconstrictor(s); possibly TxA2.

\section{INTRODUCTION}

Obesity is a fast growing problem worldwide (James, 2004) and is associated with an increasing risk of cardiovascular morbidity and mortality, especially when it is associated with other risk factors in the metabolic syndrome (Hu et al., 2004). However, the root causes of cardiovascular dysfunction associated with the metabolic syndrome still remain poorly defined (Krentz et al., 2009). The endothelium regulates vascular tone through the production of nitric oxide (NO), prostacyclin and hyperpolarizing factors. The endothelium is affected in metabolic syndrome (Eckel et al., 2005; Frisbee and Delp, 2006). Indeed, studies in human (Arkin et al., 2008) or in obese Zucker rats, a model of hyperphagia-induced metabolic syndrome, have reported endothelium dysfunction in several vascular beds (Zanchi et al., 1995) associated with a reduced NO bioavailability (Bohlen, 2004). Resistance arteries are strongly affected in metabolic disorders (Frisbee and Stepp, 2001; Stepp et al., 2004; Frisbee and Delp, 2006; Krentz et al., 2009) due to increased reactive oxygen species (ROS) production and consequently reduced NO bioavailability (Phillips et al., 2005; Busija et al., 2006; Roberts et al., 2006). Several studies suggest that cyclooxygenase (COX) derivatives might also be involved in this vascular impairment. Indeed, metabolic syndrome is also associated with increased thromboxane $\mathrm{A}_{2}\left(\mathrm{TXA}_{2}\right)$-mediated vasoconstriction and endothelium dysfunction (Xiang et al., 2006, 2008). These studies suggest that COX2 might be involved in this production of TXA .

Aging, per se is also associated to a gradual endothelium dysfunction both in human (Egashira et al., 1993; Taddei et al., 1995) and animal models of aging (Koga et al., 1989; Kung and Luscher, 1995). Again, an excessive ROS production reduces NO bioavailability (Wenzel et al., 2008; Herrera et al., 2010). Nevertheless, the involvement of COX2-derived prostanoids remains a matter of controversy. Several studies have reported an increased COX2-derived $\mathrm{TXA}_{2}$ production with aging, attenuating endothelium-mediated vasorelaxation (Koga et al., 1989) while other studies (Kung and Luscher, 1995) argued for an increase ROS production only. A recent study using a mouse model of obesity reported that aging up-regulates expression of inflammatory mediators in adipose tissues and showed an increased COX2 expression level (Wu et al., 2007). Nevertheless, no study has yet investigated the concomitant effect of aging and metabolic syndrome on the endothelium and its vasodilator capacity. The purpose of the present study was thus 
to assess the effect of aging associated with metabolic syndrome on endothelium-mediated relaxation. We hypothesized that in old obese rats COX2 derived prostanoids may further impair endothelium-mediated dilation. We compared acetylcholine-mediated relaxation in first order mesenteric arteries isolated from young and old obese Zucker rats, a model of metabolic syndrome, and defined the mechanism involved in the alteration observed.

\section{MATERIALS AND METHODS ANIMALS}

Three- and 12-month-old male lean and obese Zucker rats were purchased from Charles River (L'Arbresles, France) and anesthetized (Isoflurane, 2.5\%). The right femoral artery was then cannulated for blood pressure measurement as previously described (Ben Driss et al., 2000). Animals were then sacrificed by $\mathrm{CO}_{2}$ inhalation after collecting blood on heparin. The gut excised and the mesenteric arteries gently dissected. Blood glucose was measured as previously described (Frisbee and Stepp, 2001; Katakam et al., 2005; Bouvet et al., 2007).

In a separated series of experiments 12-month-old male lean and obese Zucker rats were treated with the COX2 inhibitor Celecoxib (25 mg/kg/day, forced feeding once a day, 21 days).

The procedure followed in the care and euthanasia of the study animals was in accordance with the European Community Standards on the Care and Use of Laboratory Animals (Ministère de l'Agriculture, France, authorization No. 6422).

\section{PHARMACOLOGICAL PROFILE OF THE ARTERIES}

First order mesenteric arteries were isolated and mounted on a wire-myograph (DMT, Aarhus, Denmark), as previously described (Henrion et al., 1992; Loufrani et al., 2002). Briefly, two tungsten wires ( $25 \mu \mathrm{m}$ diameter) were inserted in the lumen of the arteries and fixed to a force transducer and a micrometer, respectively. A wall tension equivalent to a pressure of $100 \mathrm{mmHg}$ was then applied. Arteries were bathed in a physiological salt solution (PSS) maintained at a $\mathrm{pH}$ of 7.4, a $\mathrm{PO}_{2}$ of $160 \mathrm{mmHg}$ and $\mathrm{PCO}_{2}$ of $37 \mathrm{mmHg}$. Cumulative concentration-response curves to acetylcholine were contracted with phenylephrine $(1-3 \mu \mathrm{mol} / \mathrm{L}$ in order to reach $50 \%$ of maximal contraction) (Loufrani et al., 2002). Cumulative concentrationresponse curves were repeated after addition of one of the following agent: the NO-synthase blocker L-NAME $(100 \mu \mathrm{mol} / \mathrm{L})$, the non-specific COX inhibitor indomethacin $(10 \mu \mathrm{mol} / \mathrm{L})$, the COX2 inhibitor NS398 $(10 \mu \mathrm{mol} / \mathrm{L})$ or the $\mathrm{TXA}_{2} / \mathrm{PGH}_{2}$ (TP) receptor antagonist SQ29548 (10 $\mathrm{mol} / \mathrm{L})$ (Racz et al., 2009). Endothelium-independent vasorelaxation was assessed with a CRC to sodium nitroprusside (SNP). Contraction to phenylephrine ( $1 \mathrm{nmol} / \mathrm{L}$ to $10 \mu \mathrm{mol} / \mathrm{L}$ ) and to $\mathrm{U} 46619$ (stable $\mathrm{TxA}_{2}$ mimetic, $1 \mathrm{nmol} / \mathrm{L}$ to $10 \mu \mathrm{mol} / \mathrm{L}$ ) (Bolla et al., 2002) was assessed on a different arterial segment.

\section{WESTERN BLOT ANALYSIS}

Arterial segments were homogenized and proteins ( $25 \mu \mathrm{g}$ total protein from each sample) were separated by SDS-PAGE using a $4 \%$ stacking gel followed by a 10\% running gel. Proteins were detected with specific antibodies directed against eNOS (Transduction Laboratories) 1:1000 or COX2 (1:500, Santa Cruz Biotechnology) in TBST. Protein expression was visualized using the ECL-Plus Chemiluminescence kit (Amersham) (Belin de Chantemele et al., 2009).

\section{IMMUNO-HISTOLOGICAL DETECTION OF COX2}

Cyclooxygenase-2 immunolabeling was performed as previously described (Henrion et al., 1997; Retailleau et al., 2010). Briefly, segments of mesenteric arteries were mounted in embedding medium (Tissu-Tek, Miles, Inc.), frozen in isopentane pre-cooled in liquid nitrogen, and stored at $-80^{\circ} \mathrm{C}$. Primary goat anti-COX2 polyclonal antibodies (1/200, Santa Cruz Biotechnology) were applied on the cross-sections ( $7 \mu \mathrm{m}$ thick) followed by the fluorescent secondary antibody (1/200, Fluoroprobes). In negative control experiments the primary antibody was omitted. Positive control experiments were performed using mesenteric arteries from lipopolysaccharidetreated rats (Belin de Chantemele et al., 2010). Positive staining was visualized using confocal microscopy and QED-Image software (Solamere Technology). Image analysis was performed using Histolab (Microvision). The auto-fluorescent internal and external laminas, excluded for the fluorescence quantification, were used to delimit the media. Care was taken to take all the pictures in the same condition of laser power, gain, and exposure time.

\section{BLOOD PROSTANOIDS MEASUREMENT}

Blood samples were withdrawn from the femoral artery and placed in ice-cold polypropylene tubes containing EDTA plus indomethacin and centrifuged immediately at $3000 \mathrm{rpm}$ for $15 \mathrm{~min}$ at $4^{\circ} \mathrm{C}$ and then stored at $-80^{\circ} \mathrm{C}$. Plasma samples were acidified with glacial acetic acid to $\mathrm{pH} 3$ and then applied to octadecylsilyl (ODS) silica columns, washed with $15 \%$ aqueous ethanol and petroleum ether. The prostanoids were eluted with methyl formate. The eluent was evaporated to dryness under vacuum and the residue was dissolved in $400 \mathrm{~L}$ assay buffer. Thromboxane $\mathrm{B}_{2}$, 6-keto-PGF ${ }_{1}$ alpha, and 8 -isoprostane concentrations were measured using commercially available kits (Cayman Chemical). Hydrolysis with $\mathrm{KOH} \mathrm{15 \%}$ $\left(40^{\circ} \mathrm{C}, 60 \mathrm{~min}\right.$ followed by $\left.\mathrm{KH}_{2} \mathrm{PO}_{4} 1 \mathrm{M}\right)$ was performed before 8 -isoprostane measurement). The total prostanoids concentration was measured as $\mathrm{pg} / \mathrm{mL}$.

\section{HISTOLOGICAL ANALYSIS}

In order to determine the cross-sectional area of mesenteric arteries, blood vessels were dissected under a microscope, mounted between two glass micropipettes and submitted to intraluminal pressure $(100 \mathrm{mmHg})$. Arteries were bathed in a calcium-free PSS containing SNP $(10 \mu \mathrm{mol} / \mathrm{L})$. Arteries were then fixed in CARSON solution and embedded in Epon E812 resin. Semi-thin sections were stained with toluidine blue and observed under a DMR microscope (Leica). Image analysis was performed as previously described using the Histolab software (Microvision, Paris, France) (Belin de Chantemele et al., 2009).

\section{STATISTICAL ANALYSIS}

Results are expressed as mean \pm SEM. Significance of the difference between arteries was determined by ANOVA (one-factor ANOVA or ANOVA for consecutive measurements, when appropriate). Mean values were compared by unpaired $t$-test or by the Bonferroni test for multigroup comparisons. Values of $P<0.05$ were considered to be significant. 


\section{RESULTS \\ PHYSIOLOGICAL PARAMETERS}

Rat body weight was significantly higher in obese Zucker rats than in lean rats, independent of age, and body weight was higher in 12-month-old rats than in young rats (Table 1). Mean arterial blood pressure was not affected by aging in lean rats or by metabolic syndrome in young animals. Nevertheless, mean arterial pressure was slightly, but significantly, increased in old obese Zucker rats compare to young or old lean animals. Blood glucose was not significantly affected by aging in lean rats and by metabolic syndrome in young animals. However glycemia was significantly increased in old obese Zucker rats compared to young or old lean rats (Table 1).

\section{ENDOTHELIUM FUNCTION}

Acetylcholine induced a concentration-dependent relaxation in isolated mesenteric arteries. Acetylcholine-mediated relaxation was significantly reduced in obese Zucker rats compared to lean rats and the combination of metabolic syndrome and aging further impaired endothelium-dependent relaxation (Figures 1A,B).

NO-synthesis inhibition with L-NAME reduced acetylcholinemediated relaxation. Aging did not significantly affect the inhibitory effect of L-NAME in lean rats. On the other hand, in both young and old obese Zucker rats the inhibitory effect of L-NAME was significantly reduced compared to lean rats (Figure 1B). Indeed, acetylcholine-mediated maximal relaxation was inhibited by $78 \pm 7 \%$ in young lean rats (Figure 1C) and by $49 \pm 6 \%$ in young obese Zucker rats. L-NAME inhibited the relaxation by $75 \pm 7 \%$ in old lean rats and by $56 \pm 6 \%$ in old obese Zucker rats $(P<0.05$ versus lean).

Indomethacin did not significantly affect acetylcholine-mediated relaxation in young obese Zucker and lean rats (Figure 1A). On the other hand, indomethacin further reduced acetylcholine-

Table 1 | Body weight, mean arterial pressure, and blood glucose measured in lean and obese Zucker rats aged 4 or 12 months.

\begin{tabular}{|c|c|c|c|c|}
\hline \multirow[b]{2}{*}{ Age (months) } & \multicolumn{2}{|c|}{ Lean rats } & \multicolumn{2}{|c|}{ Obese Zucker rats } \\
\hline & 4 & 12 & 4 & 12 \\
\hline \multicolumn{5}{|c|}{ VEHICLE-TREATED RATS } \\
\hline Body weight (g) & $335 \pm 11$ & $388 \pm 14^{*}$ & $527 \pm 28^{*}$ & $721 \pm 29 * \#$ \\
\hline $\begin{array}{l}\text { Mean arterial } \\
\text { pressure }(\mathrm{mmHg})\end{array}$ & $97 \pm 3$ & $103 \pm 4$ & $101 \pm 5$ & $123 \pm 6^{* \#}$ \\
\hline $\begin{array}{l}\text { Blood glucose } \\
\text { (mmol/L) }\end{array}$ & $8.6 \pm 0.7$ & $8.99 \pm 0.9$ & $9.58 \pm 0.9$ & $12.38 \pm 1.0^{* * \#}$ \\
\hline \multicolumn{5}{|c|}{ CELECOXIB-TREATED RATS } \\
\hline Body weight (g) & & $391 \pm 12^{*}$ & & $696 \pm 34^{* \#}$ \\
\hline $\begin{array}{l}\text { Mean arterial } \\
\text { pressure }(\mathrm{mmHg})\end{array}$ & & $101 \pm 3^{*}$ & & $126 \pm 5^{* \#}$ \\
\hline $\begin{array}{l}\text { Blood glucose } \\
(\mathrm{mmol} / \mathrm{L})\end{array}$ & & $8.2 \pm 1.0$ & & $13.11 \pm 1.2^{* \#}$ \\
\hline
\end{tabular}

Rats were treated with the COX2 inhibitor Celecoxib or not (mean $\pm S E M, n=8$ per group).

${ }^{*} P<0.05$, young or old obese Zucker versus young lean rats.

${ }^{\#} P<0.05$, old obese Zucker rats versus old lean rats. mediated vasorelaxation in old lean animals (Figure 1B), whereas indomethacin increased acetylcholine-mediated vasorelaxation in old obese Zucker rats (Figure 1B).

Precontraction prior to the addition of acetylcholine was similar in the four groups (Figure 1D).

The endothelium dysfunction associated with metabolic syndrome, aging, or the combination of aging plus metabolic syndrome was not associated with a change in eNOS expression level (Figure 1E).

Endothelium-independent relaxation (SNP) was not affected by aging or by metabolic syndrome (Figure 2A).

\section{CONTRACTILITY}

Contraction to phenylephrine was not affected by aging or chronic COX2 inhibition (data not shown) whereas contraction to U46619 was significantly higher in 12-month-old obese Zucker rats (maximal contraction: $16 \pm 1.6 \mathrm{mN}, n=8$ ) than in 12-month-old lean rats $(11 \pm 1.2 \mathrm{mN}, n=8)$ or than in 3 -month-old rats $(10 \pm 1.4 \mathrm{mN}$ in lean rats and $12 \pm 1.4 \mathrm{mN}$ in obese rats, $n=10$ per group). In 12-month-old lean rats chronically treated with Celecoxib, U46619induced contraction was significantly reduced $(11 \pm 1.5 \mathrm{mN}, n=8)$. The EC50 for U46619 was not affected by aging or metabolic syndrome (data not shown).

\section{VASCULAR REMODELING}

Arterial (luminal) diameter was reduced in obese Zucker rats compared to lean rats (significant in young animals only) and increased in old compared to young rats (Figure 2B). By contrast, media cross-section was higher in obese Zucker rats than in lean rats (again, significant in young animals only) and higher in old than in young rats (Figure 2C). Media to lumen ratio was significantly higher in old Zucker obese rats compared to lean animals (Figure 2D). In celecoxib-treated old rats media to lumen ratio remained significantly higher in old Zucker obese rats compared to lean animals $(0.94 \pm 0.11$ in obese Zucker rats versus $0.63 \pm 0.09$ in lean rats, $n=8$ per group, $P<0.05)$.

\section{ROLE OF COX2 DERIVED PROSTANOIDS IN ENDOTHELIUM-MEDIATED RELAXATION}

Acute COX2 inhibition with NS398 did not affect acetylcholinemediated relaxation in young lean and obese Zucker rats but significantly improved acetylcholine-mediated relaxation in old obese Zucker rats (Figure 3A). No effect of NS398 was observed in old lean rats (Figure $\mathbf{3 A}$ ).

TP receptor inhibition with SQ29548 did not affect acetylcholine-mediated vasorelaxation in young lean and obese Zucker rats while it significantly improved endothelium-dependent relaxation in old obese Zucker rats (Figure 3B).

In old obese Zucker rats plasma $\mathrm{TxB}_{2}$ (stable metabolite of $\mathrm{TxA}_{2}$ ), 6-keto-PGF ${ }_{1}$ alpha (stable métabolite of $\mathrm{PGI}_{2}$ ) and 8-isoprostane were significantly higher than in young rats (lean or obese) and than in old lean rats (Figure 4). In old obese Zucker rats chronically treated with Celecoxib plasma plasma $\mathrm{TxB}_{2}$ and 6-keto-PGF $\mathrm{Palpha}_{1}$ was reduced to the level found in lean animals. The treatment did not significantly change blood 8-isoprostane level. In young obese Zucker rats blood $\mathrm{TxB}_{2}$ was not significantly higher than in young lean rats (Figure 4). 

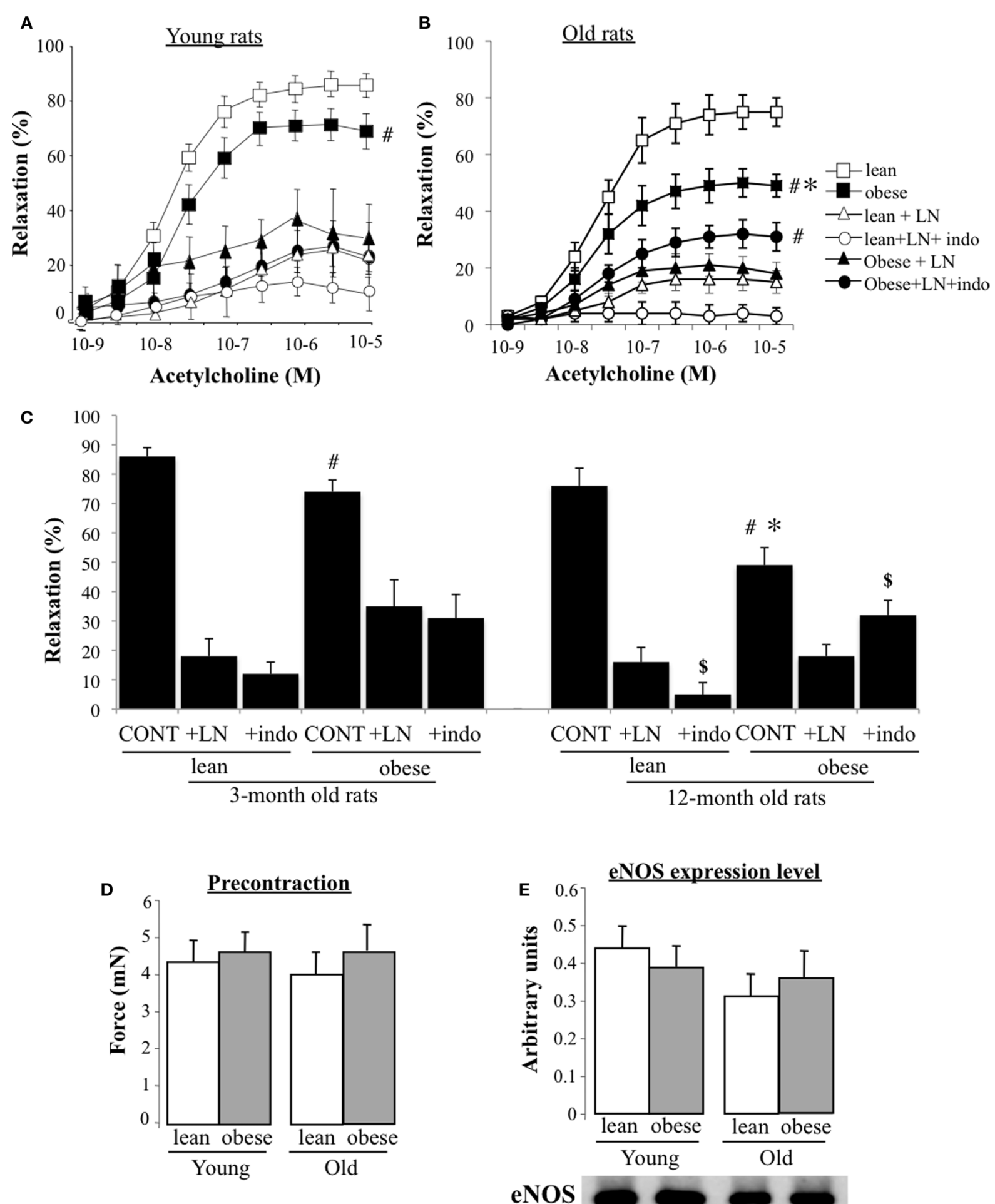

$\beta$-actin

FIGURE 1 |Acetylcholine-mediated relaxation in mesenteric resistance arteries isolated from young (A) or old (B) lean and obese Zucker rats. Concentration-response curves to acetylcholine were repeated after incubation with L-NAME (LN) and then with L-NAME plus indomethacin ( $\mathrm{LN}+$ indo). Bargraphs $\mathbf{( C )}$ represent the maximal relaxation obtained in each group (taken from $\mathbf{A}$ and $\mathbf{B}$ ). (D) Precontraction applied to the arteries before adding acetylcholine. (E) eNOS and $\beta$-actin expression level determined using Western blot. Mean \pm SEM is presented ( $n=8$ per group). ${ }^{*} P<0.01$, old versus young rats. ${ }^{\#} P<0.01$, obese versus lean rats. ${ }^{\$} P<0.01$, indo versus LN. 


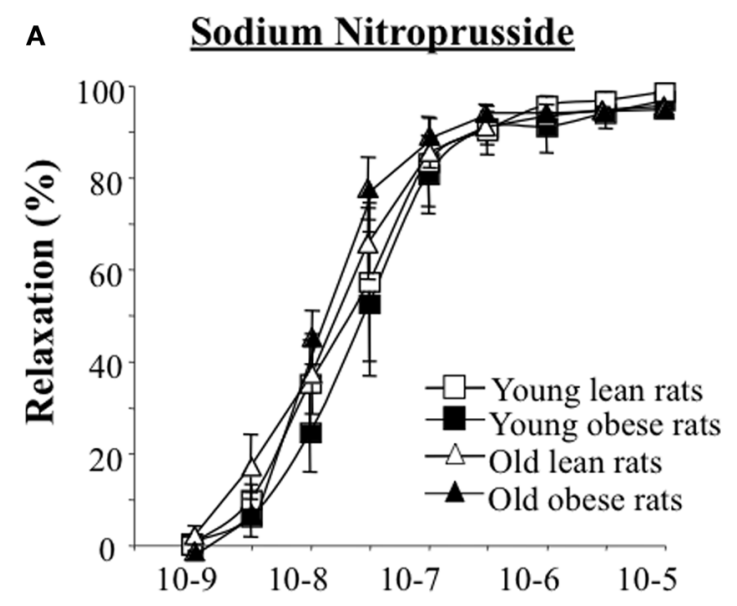

Sodium nitroprusside (M)
Medial cross section

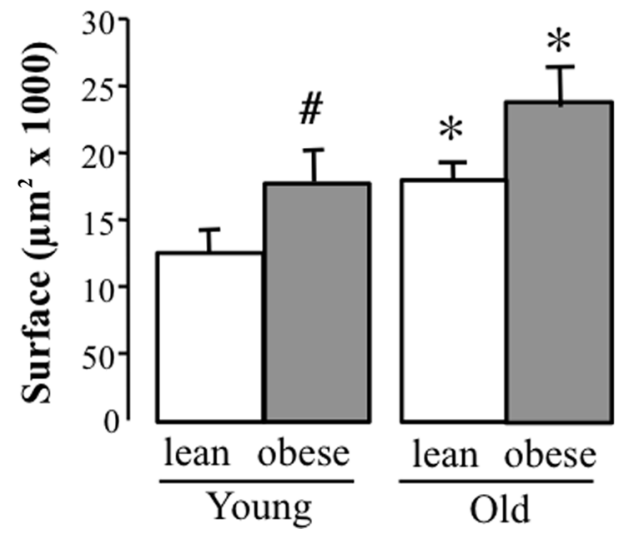

B

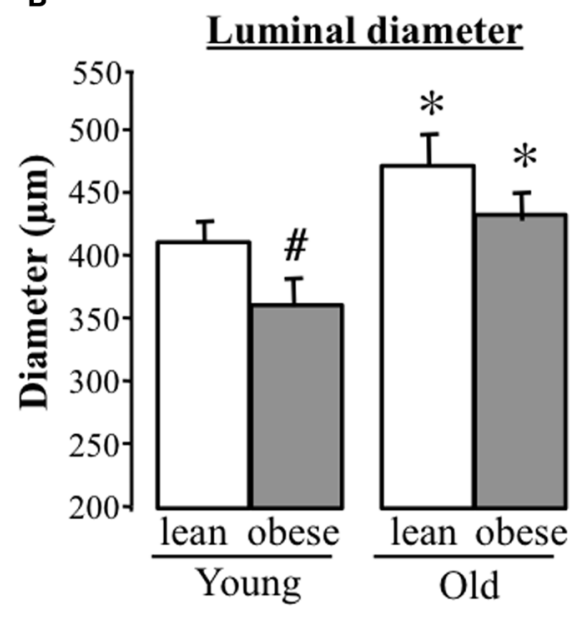

D Media / Lumen ratio

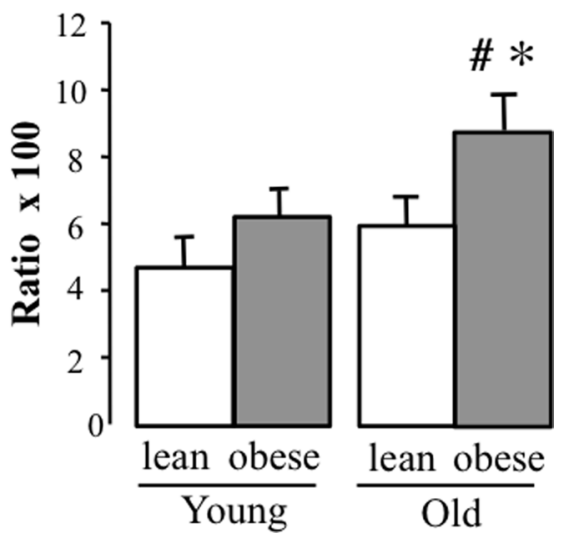

FIGURE 2 | Sodium nitroprusside-mediated relaxation in mesenteric arteries isolated from lean and obese Zucker rats aged 3 (young) or 12 months (old) (A). Luminal diameter, media cross-section, and media/lumen ratio are shown in (B-D) respectively. Mean $\pm S E M$ is presented ( $n=8$ per group). ${ }^{*}<<0.01$, old versus young rats. ${ }^{\#} P<0.01$, obese versus lean rats.

The presence of COX2 was confirmed using immunostaining and Western blot (Figure 5). Both metabolic syndrome and aging were associated with an increased COX2 expression, which was further enhanced by the combination of metabolic syndrome and aging. The endothelium and the smooth muscle layers were both labeled.

To confirm the role of COX2 in the impaired endothelium function, old obese Zucker rats were treated chronically with the COX2 inhibitor Celecoxib. Chronic Celecoxib restored the endothelium function in old obese Zucker rats without significantly affecting acetylcholine-mediated relaxation in old lean rats (Figure 6). In both lean and obese old Zucker rats L-NAME abolished acetylcholine-mediated dilation and indomethacin had no significant effect (Figure 6). Similarly, in lean and obese old Zucker rats chronically treated with celecoxib, SQ29548 (Figure 6) and NS398 (data not shown) had no significant effect on acetylcholinemediated dilation.

\section{DISCUSSION}

The novel finding of the present study is that the combined effect of metabolic syndrome and aging in a rat model, the obese Zucker rat, further impaired endothelium-dependent dilation due to COX2dependent production of TxA.

Endothelium-mediated relaxation was lower in old rats, especially in old obese Zucker rats, in agreement with previous studies although they were performed in young obese Zucker rats (Frisbee and Stepp, 2001; Katakam et al., 2005; Bouvet et al., 2007) or old control, or lean, rats (Ishida et al., 2003; 


\section{A}

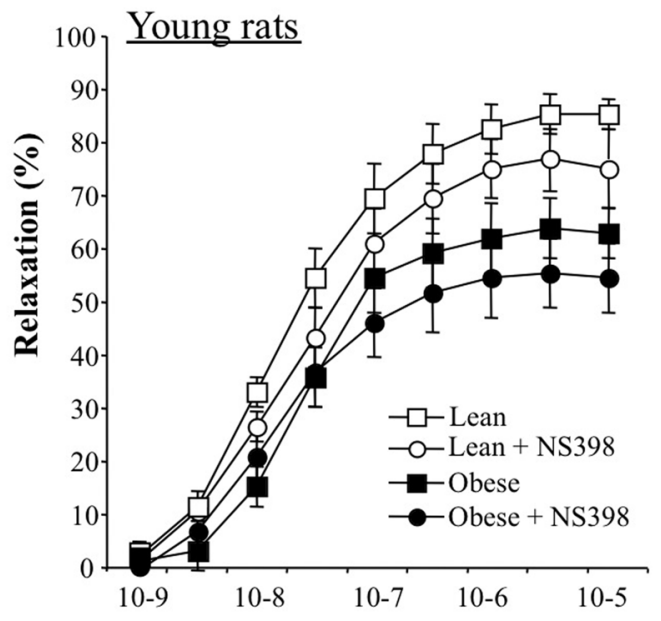

Acetylcholine (M)

B

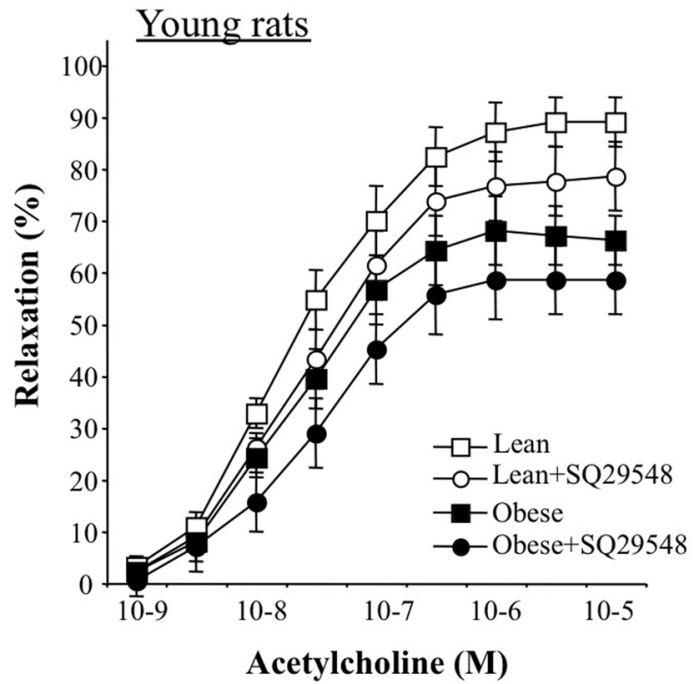

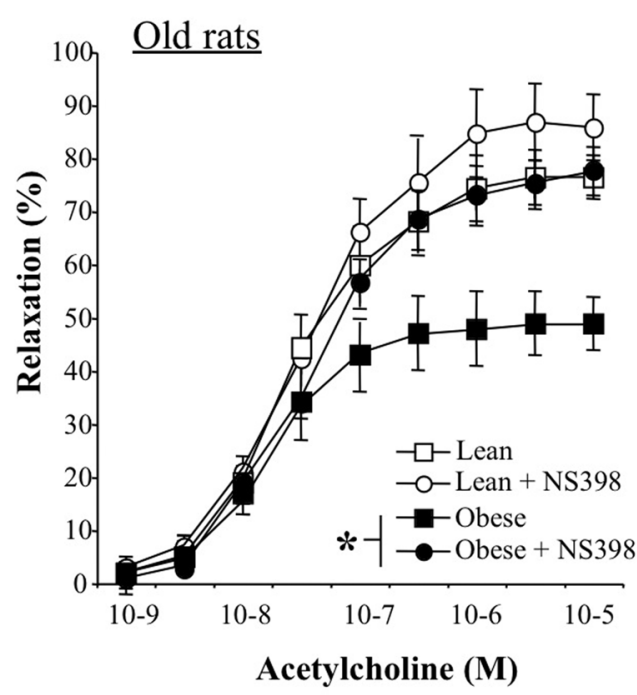

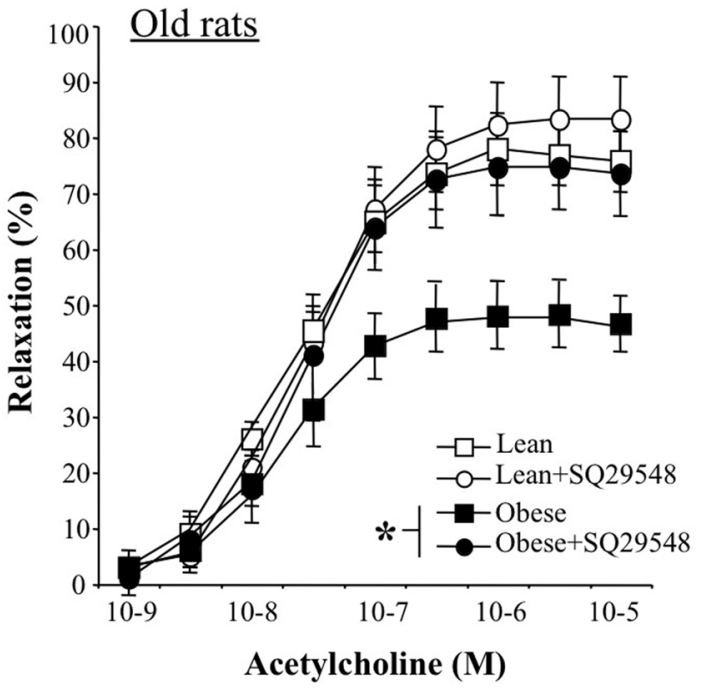

FIGURE 3 | Effect of COX2 inhibition with NS398 (A) or TxA $/ 2 \mathrm{PGH}_{2}$ receptor blockade with SQ29548 (B) on acetylcholine-mediated relaxation in mesenteric resistance arteries isolated from young (A) or old (B) lean and obese Zucker rats. Mean \pm SEM is presented ( $n=8$ per group). ${ }^{*} P<0.01$, effect of NS398 (A) or SQ29548 (B).

Dumont et al., 2008). Similarly, acetylcholine-mediated relaxation is reduced in 7-month-old obese Zucker rats compared to 5-month-old animals (Subramanian and MacLeod, 2003). We also found a reduction in L-NAME sensitive endotheliummediated relaxation in both young and old obese Zucker rats. Although L-NAME blocks selectively NO-dependent dilation, this reduction was not associated with a change in eNOS expression level. This is in agreement with previous works performed in 2-year-old rats (Yan et al., 2007; Dumont et al., 2008) and in young obese Zucker rats (Karagiannis et al., 2003; Bouvet et al., 2007). Vascular smooth muscle cells response to the NO donor SNP was similar in the different groups, in agreement with previous studies (Steinberg et al., 1996; Oltman et al., 2005, 2006;
Dumont et al., 2008). Thus observation suggests that vascular smooth muscle cells sensitivity to $\mathrm{NO}$ was not affected by aging or metabolic syndrome.

In lean old rats, part of the dilation was sensitive to indomethacin, suggesting the involvement of vasodilator prostanoids, in agreement with a previous study in older rats (Heymes et al., 2000). Relaxation resistant to L-NAME and indomethacin in young rats and in old obese Zucker rats was probably due to EDHF as previously shown in various vascular territories (Feletou and Vanhoutte, 2009). In addition, EDHF-dependent relaxation is reduced in obese Zucker mesenteric arteries (Young et al., 2008). Nevertheless, this issue was not investigated in the present study which focused on the involvement of COX-derived prostanoids. 


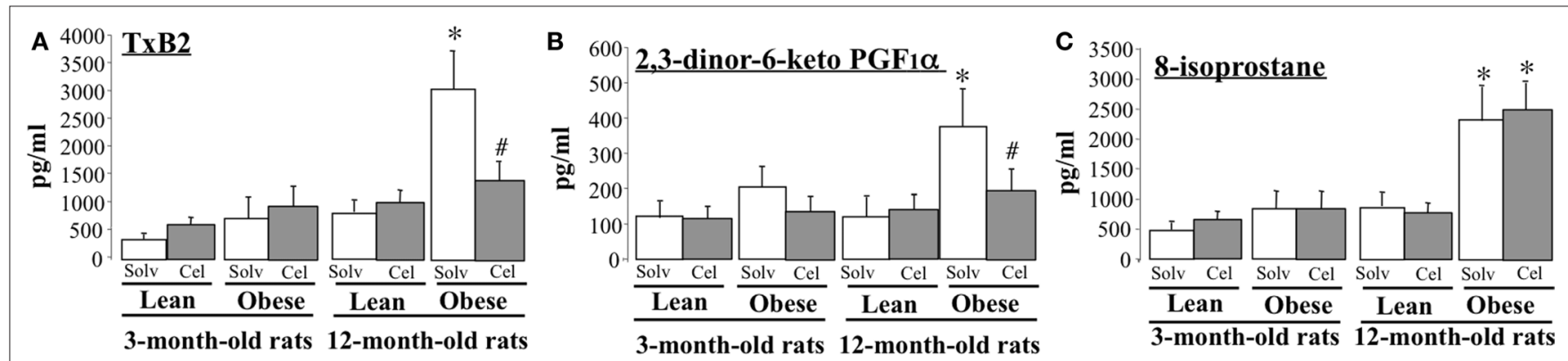

FIGURE 4 | Plasma TxB inhibitor Celecoxib (Cel) or its solvent (Solv). Mean \pm SEM is presented ( $n=8$ per group). ${ }^{*} P<0.01$, obese versus lean rats. ${ }^{\#} P<0.01$, Celecoxib versus solvent.
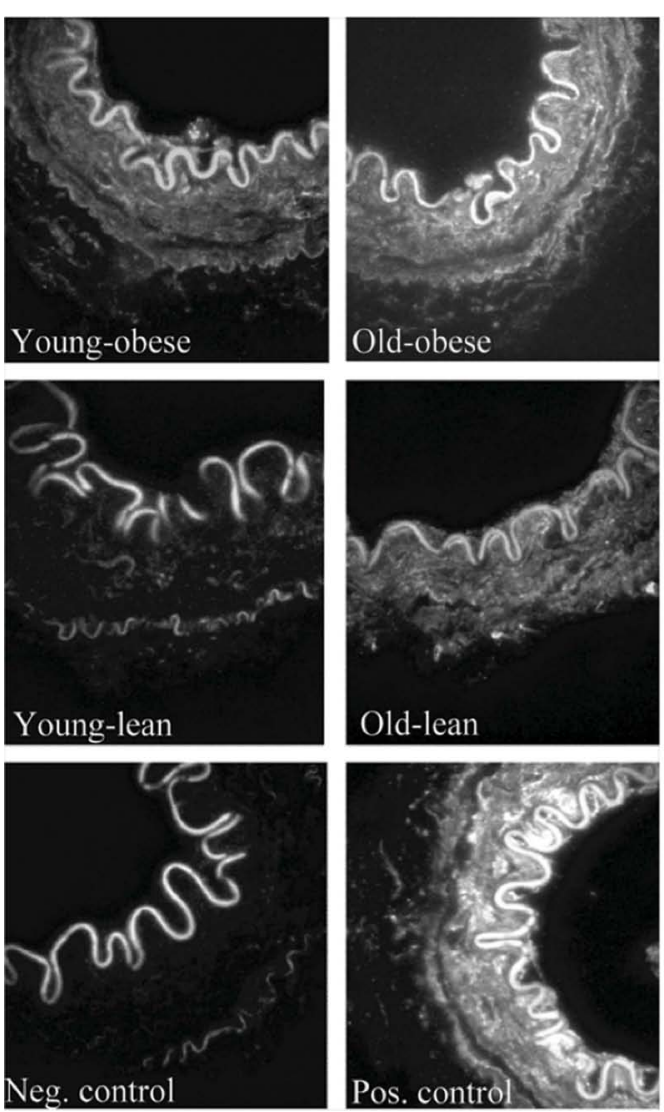

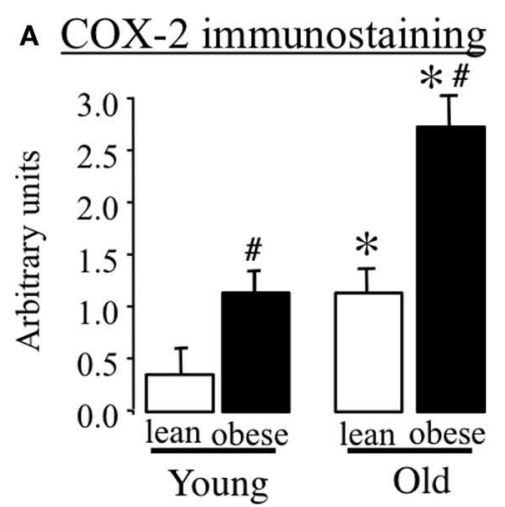

B

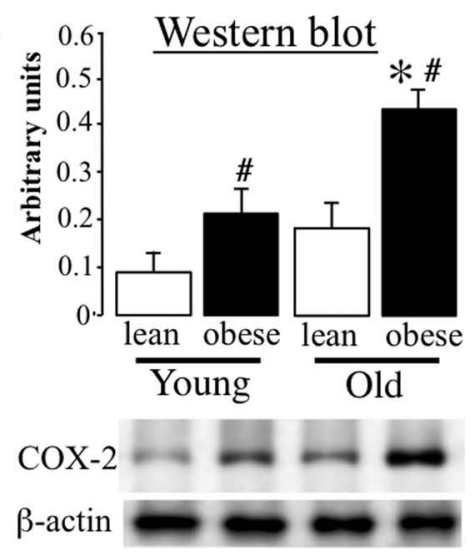

FIGURE 5 | (A) Detection of COX2 in mesenteric resistance arteries isolated from young or old lean and obese Zucker rats using immunostaining and confocal microscopy. A negative control was obtained by omitting the primary antibody (Neg. control) and a positive control was obtained using arteries from a lipopolysaccharide-treated rat (Pos. control). Quantification of the positive labeling is shown in the upper bargraph. (B) Quantitation of COX2 and $\beta$-actin using Western blot. Mean \pm SEM is presented ( $n=8$ per group). ${ }^{*} P<0.01$, old versus young rats. ${ }^{P} P<0.01$, obese versus lean rats.
In old obese Zucker rats indomethacin improved acetylcholinemediated relaxation, suggesting the involvement of vasoconstrictor prostanoids. This vasoconstrictor prostanoid is most likely TxA produced by COX2 as COX2 inhibition with NS398 and $\mathrm{TxA}_{2} / \mathrm{PGH}_{2}$ receptor blockade with SQ29548 similarly improved relaxation. In addition, contraction induced by the TxA mimetic U49619 was higher in old obese Zucker rats whereas phenylephrine-induced con- traction was not affected. The relationship between COX2, adrenergic receptor and TP receptors remains to be further investigated. Our findings are in agreement with previous reports in old rats (Briones et al., 2005; Gendron et al., 2007; Kang et al., 2007) and in both young (Dey et al., 2004) and old obese rats (Gendron et al., 2007) showing the involvement of COX2-derived vasoconstrictor agents in old rats. Similarly, $\mathrm{TxA}_{2}$ impairs endothelium-mediated dilation 

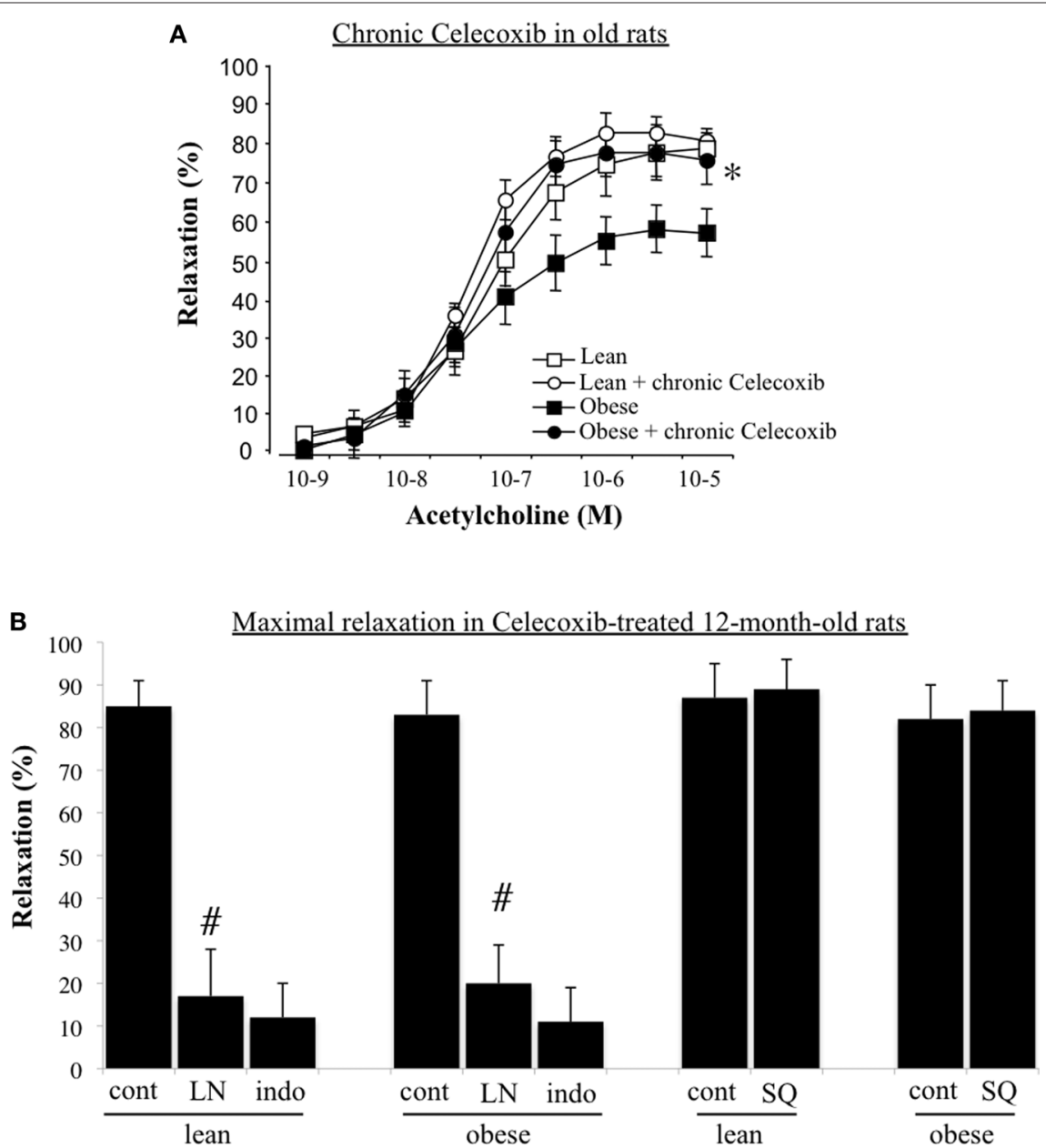

FIGURE 6 | Acetylcholine-mediated relaxation in mesenteric resistance arteries isolated from or old lean and obese Zucker rats (A). Rats were treated chronically with the COX2 inhibitor Celecoxib or its solvent.

Mean \pm SEM is presented ( $n=8$ per group). Acetylcholine-mediated relaxation was repeated in the presence of L-NAME (LN), L-NAME plus indomethacin (indo), or SQ29548 (SQ) and the effect is shown in the bargraph (B). ${ }^{*} P<0.01$, effect of the chronic treatment with Celecoxib. ${ }^{P} P<0.001$, effect of L-NAME. of arteries of young obese Zucker rats in response to reduced oxygen tension (Goodwill et al., 2008). In addition, $\mathrm{TxB}_{2}$ blood level (the stable metabolite of $\mathrm{TxA}_{2}$ ) was elevated in young (Dey et al., 2004, not significant in the present study) and old (present study) obese Zucker rats. Furthermore, a simultaneous reduction in prostacyclin production might increase endothelial dysfunction as previously shown in Zucker rats vascular cells (Hodnett et al., 2009). Nevertheless, blood levels of prostanoids, as measured in the present study, do not reflect vascular production only. Indeed blood measurements show that old obese Zucker rats have oxidative stress (increased isoprostane) and inflammation with systemic increased $\mathrm{TxA}_{2}$ and prostacyclin levels; one being vasoconstrictor, the other vasodilator. COX2 may produce both, at least in vascular cells (Wheeler-Jones, 2008; Retailleau et al., 2010) and both were reduced by chronic celecoxib. This might, at least in part, explain the absence of effect of celecoxib on blood pressure in old obese Zucker rats. Nevertheless, the involvement of COX2derived $\mathrm{TxA}_{2}$ in old obese Zucker rats was confirmed in arteries of rats chronically treated with Celecoxib.
Old obese Zucker rat were slightly, but significantly hyperglycemic and hypertensive at the age of 12 months (Table 1), in agreement with previous studies (Oltman et al., 2005). Nevertheless, hyperglycemia in old Zucker rats $(+30 \%)$ was much lower than in Zucker diabetic rats (3- to 4-fold increase) (Oltman et al., 2005). Hypertension in old obese Zucker was associated wit a significant increase in the media to lumen ratio, an index of wall hypertrophy. This was not observed in young rats. Although it is tempting to link the rise in blood pressure found in old obese Zucker rats excessive $\mathrm{TxA}_{2}$ production, as previously shown (Matrougui et al., 1997, 2000), hypertension in old obese Zucker rats was not reduced by the chronic blockade of COX2. Several studies have shown that hyperglycemia is associated with an excessive production of COX2-derived vasoconstrictor agents (Bagi et al., 2005; Matsumoto et al., 2007). Thus hyperglycemia, elevated in old obese Zucker rats, might be the cause, at least in part, of the induction of COX2 expression. Nevertheless, this issue remains 
to be further confirmed. Furthermore, the high oxidative stress found in old obese Zucker rats, evidenced by elevated blood level of 8-isoprostane, might also induce COX2 expression (Xiang et al., 2006, 2008).

The current study predicts a worsening of microvascular regulation in metabolic syndrome associated with age due to COX2-derived TxA . Although, a chronic treatment of the rats with the COX2 inhibitor Celecoxib restored the relaxation to control level, COX2 inhibitors possess cardiovascular toxicity (Krotz et al., 2005; Dajani and Islam, 2008; Rao and Knaus, 2008).

\section{REFERENCES}

Arkin, J. M., Alsdorf, R., Bigornia, S., Palmisano, J., Beal, R., Istfan, N.,Hess, D., Apovian, C. M., and Gokce, N. (2008). Relation of cumulative weight burden to vascular endothelial dysfunction in obesity. Am. J. Cardiol. 101, 98-101.

Bagi,Z., Erdei, N., Toth, A., Li, W., Hintze, T. H., Koller, A., and Kaley, G. (2005). Type 2 diabetic mice have increased arteriolar tone and blood pressure: enhanced release of COX-2-derived constrictor prostaglandins. Arterioscler. Thromb. Vasc. Biol. 25, 1610-1616.

Belin de Chantemele, E. J., Vessieres, E., Guihot, A. L., Toutain, B., Loufrani, L., and Henrion, D. (2010). Cyclooxygenase-2 preserves flow-mediated remodelling in old obese Zucker rat mesenteric arteries. Cardiovasc. Res. 86, 516-525.

Belin de Chantemele, E. J., Vessieres, E., Guihot, A. L., Toutain, B., Maquignau, M., Loufrani, L., and Henrion, D. (2009). Type 2 diabetes severely impairs structural and functional adaptation of rat resistance arteries to chronic changes in blood flow. Cardiovasc. Res. 81, 788-796.

Ben Driss, A., Devaux, C., Henrion, D., Duriez, M., Thuillez, C., Levy, B. I., and Michel, J. B. (2000). Hemodynamic stresses induce endothelial dysfunction and remodeling of pulmonary artery in experimental compensated heart failure. Circulation 101, 2764-2770.

Bohlen, H. G. (2004). Protein kinase betaII in Zucker obese rats compromises oxygen and flow-mediated regulation of nitric oxide formation. Am. J. Physiol. Heart Circ. Physiol.286, H492-H497.

Bolla, M., Matrougui, K., Loufrani, L., Maclouf, J., Levy, B., Levy-Toledano, S., Habib, A., and Henrion, D. (2002).p38 mitogen-activated protein kinase activation is required for thromboxaneinduced contraction in perfused and pressurized rat mesenteric resistance arteries. J. Vasc. Res. 39, 353-360.

Bouvet, C., Belin de Chantemele, E., Guihot, A. L., Vessieres, E., Bocquet,
A., Dumont, O., Jardel, A., Loufrani, L., Moreau, P., and Henrion, D. (2007). Flow-induced remodeling in resistance arteries from obese Zucker rats is associated with endothelial dysfunction. Hypertension 50, 248-254.

Briones, A. M., Montoya, N., Giraldo, J., and Vila, E. (2005). Ageing affects nitric oxide synthase, cyclooxygenase and oxidative stress enzymes expression differently in mesenteric resistance arteries. Auton. Autacoid Pharmacol. 25, 155-162.

Busija, D. W., Miller, A. W., Katakam, P., and Erdos, B. (2006). Adverse effects of reactive oxygen species on vascular reactivity in insulin resistance.

Dajani, E. Z., and Islam, K. (2008). Cardiovascular and gastrointestinal toxicity of selective cyclo-oxygenase-2 inhibitors in man. J. Physiol. Pharmacol. 59(Suppl. 2), 117-133.

Dey, A., Williams, R. S., Pollock, D. M., Stepp, D. W., Newman, J. W., Hammock, B. D., and Imig, J. D. (2004). Altered kidney CYP2C and cyclooxygenase-2 levels are associated with obesity-related albuminuria. Obes. Res. 12, 1278-1289.

Dumont, O., Pinaud, F., Guihot, A. L., Baufreton, C., Loufrani, L., and Henrion, D. (2008). Alteration in flow (shear stress)-induced remodelling in rat resistance arteries with aging: improvement by a treatment with hydralazine. Cardiovasc. Res. 77, 600-608.

Eckel, R. H., Grundy, S. M., and Zimmet, P.Z. (2005). The metabolic syndrome. Lancet 365, 1415-1428.

Egashira, K., Inou, T., Hirooka, Y., Kai, H., Sugimachi, M., Suzuki, S., Kuga, T., Urabe, Y., and Takeshita, A. (1993). Effects of age on endothelium-dependent vasodilation of resistance coronary artery by acetylcholine in humans. Circulation 88, 77-81.

Feletou, M., and Vanhoutte, P. M. (2009). EDHF: an update. Clin. Sci. 117, 139-155.

Frisbee, J. C., and Delp, M. D. (2006). Vascular function in the metabolic synAntioxid. Redox Signal. 8, 1131-1140.

In conclusion we found that $\mathrm{COX} 2$-derived $\mathrm{TxA}_{2}$ reduced endothelium-mediated relaxation in mesenteric arteries of old obese Zucker rats, a model of metabolic syndrome.

\section{ACKNOWLEDGMENTS}

We thank the local Animal Care Unit of the University of Angers and Jérôme Roux, Pierre Legras, Dominique Gilbert for their kind help in treating the rats. Supports: Foundation for Medical Research (FRM: Fondation pour la Recherche Médicale), Paris, France. Eric J. Belin de Chantemèle was a post-doctoral fellow of the Centre National d'Etudes Spatiales (CNES), France.

drome and the effects on skeletal muscle perfusion:lessons from the obese Zucker rat. Essays Biochem. 42, 145-161.

Frisbee, J. C., and Stepp, D. W. (2001) Impaired NO-dependent dilation of skeletal muscle arterioles in hypertensive diabetic obese Zucker rats. Am. J. Physiol. Heart Circ. Physiol. 281, H1304-H1311.

Gendron, M. E., Thorin-Trescases, N., Villeneuve, L., and Thorin, E. (2007). Aging associated with mild dyslipidemia reveals that COX-2 preserves dilation despite endothelial dysfunction. Am. J. Physiol. Heart Circ. Physiol. 292, H451-H458.

Goodwill,A. G., James, M.E., and Frisbee, J.C. (2008). Increased vascular thromboxane generation impairs dilation of skeletal muscle arterioles of obese Zucker rats with reduced oxygen tension. Am. J. Physiol. Heart Circ. Physiol. 295, H1522-H1528.

Henrion, D., Dechaux, E., Dowell, F. J. Maclour, J., Samuel, J. L., Levy, B. I., and Michel, J. B. (1997). Alteration of flow-induced dilatation in mesenteric resistance arteries of L-NAME treated rats and its partial association with induction of cyclo-oxygenase-2. Br. J. Pharmacol. 121, 83-90.

Henrion, D., Laher, I., Laporte, R., and Bevan, J. A. (1992). Angiotensin II amplifies arterial contractile response to norepinephrine without increasing Ca++influx: role of protein kinase C. J. Pharmacol. Exp. Ther. 261, 835-840.

Herrera, M. D., Mingorance, C. Rodriguez-Rodriguez, R., and Alvarez de Sotomayor, M. (2010). Endothelial dysfunction and aging: an update. Ageing Res. Rev. 9, 142-152.

Heymes, C., Habib, A., Yang, D. Mathieu, E., Marotte, F., Samuel, J., and Boulanger, C. M. (2000). Cyclooxygenase- 1 and -2 contribution to endothelial dysfunction in ageing. $\mathrm{Br}$. J. Pharmacol. 131, 804-810.

Hodnett, B. L., Dearman, J. A., Carter, C. B., and Hester, R. L. (2009). Attenuated PGI2 synthesis in obese Zucker rats. Am. J. Physiol. Regul. Integr. Comp. Physiol. 296, R715-R721.
Hu, G., Qiao, Q., Tuomilehto, J., Balkau, B., Borch-Johnsen, K., and Pyorala, K. (2004). Prevalence of the metabolic syndrome and its relation to all-cause and cardiovascular mortality in nondiabetic European men and women. Arch. Intern. Med. 164, 1066-1076.

Ishida, S., Hamasaki, S., Kamekou, M. Yoshitama, T., Nakano, F., Yoshikawa, A., Kataoka, T., Saihara, K., Minagoe, S., and Tei, C. (2003). Advancing age is associated with diminished vascular remodeling and impaired vasodilation in resistance coronary arteries. Coron. Artery Dis. 14, 443-449.

James, P. T. (2004). Obesity: the worldwide epidemic. Clin. Dermatol. 22, 276-280.

Kang, K. B., Rajanayagam, M. A., van der Zypp, A., and Majewski, H. (2007). A role for cyclooxygenase in aging-related changes of beta-adrenoceptor-mediated relaxation in rat aortas. Naunyn Schmiedebergs Arch. Pharmacol. 375, 273-281.

Karagiannis, J., Reid, J. J., Darby, I., Roche, P., Rand, M. J., and Li, C. G. (2003) Impaired nitric oxide function in the basilar artery of the obese Zucker rat. J. Cardiovasc. Pharmacol. 42, 497-505.

Katakam, P. V., Tulbert, C. D., Snipes, J.A., Erdos, B., Miller, A. W., and Busija, D. W. (2005). Impaired insulin-induced vasodilation in small coronary arteries of Zucker obese rats is mediated by reactive oxygen species. Am. J. Physiol. Heart Circ. Physiol. 288, H854-H860.

Koga,T., Takata,Y., Kobayashi, K., Takishita, S., Yamashita, Y., and Fujishima, M. (1989).Age and hypertension promote endothelium-dependent contractions to acetylcholine in the aorta of the rat. Hypertension 14, 542-548.

Krentz, A. J., Clough, G., and Byrne, C. D. (2009). Vascular disease in the metabolic syndrome: do we need to target the microcirculation to treat large vessel disease? J. Vasc. Res. 46, 515-526.

Krotz, F., Schiele, T. M., Klauss, V., and Sohn, H. Y. (2005). Selective COX-2 inhibitors and risk of myocardial infarction. J. Vasc. Res. 42, 312-324. 
Kung, C. F., and Luscher, T. F. (1995). Different mechanisms of endothelial dysfunction with aging and hypertension in rat aorta. Hypertension 25, 194-200.

Loufrani, L., Levy, B. I., and Henrion, D. (2002). Defect in microvascular adaptation to chronic changes in blood flow in mice lacking the gene encoding for dystrophin. Circ. Res. 91, 1183-1189.

Matrougui, K., Levy, B. I., and Henrion, D. (2000). Tissue angiotensin II and endothelin-1 modulate differently the response to flow in mesenteric resistance arteries of normotensive and spontaneously hypertensive rats. $\mathrm{Br}$. J. Pharmacol. 130, 521-526.

Matrougui, K., Maclouf, J., Levy, B. I., and Henrion, D. (1997). Impaired nitric oxide- and prostaglandin-mediated responses to flow in resistance arteries of hypertensive rats. Hypertension 30, 942-947.

Matsumoto, T., Kakami, M., Noguchi, E., Kobayashi, T., and Kamata, K. (2007). Imbalance between endotheliumderived relaxing and contracting factors in mesenteric arteries from aged OLETF rats, a model of Type 2 diabetes. Am. J. Physiol. Heart Circ. Physiol. 293, H1480-H1490.

Oltman, C. L., Coppey, L. J., Gellett, J. S., Davidson, E. P., Lund, D. D., and Yorek, M. A. (2005). Progression of vascular and neural dysfunction in sciatic nerves of Zucker diabetic fatty and Zucker rats. Am. J. Physiol. Endocrinol. Metab. 289, E113-E122.

Oltman, C. L., Richou, L. L., Davidson, E. P., Coppey, L. J., Lund, D. D., and Yorek, M. A. (2006). Progression of coronary and mesenteric vascular dysfunction in Zucker obese and Zucker diabetic fatty rats. Am. J. Physiol. Heart Circ. Physiol. 291, H1780-H1787.

Phillips, S. A., Sylvester, F. A., and Frisbee, J. C. (2005). Oxidant stress and constric- tor reactivity impair cerebral artery dilation in obese Zucker rats. Am. J. Physiol. Regul. Integr. Comp. Physiol. 288, R522-R530.

Racz,A., Veresh,Z., Erdei, N., Bagi,Z., and Koller, A. (2009). Thromboxane A(2) contributes to the mediation of flowinduced responses of skeletal muscle venules: role of cyclooxygenases 1 and 2. J. Vasc. Res. 46, 397-405.

Rao, P., and Knaus, E. E. (2008). Evolution of nonsteroidal anti-inflammatory drugs (NSAIDs): cyclooxygenase (COX) inhibition and beyond. $J$. Pharm. Pharm. Sci. 11, 81s-110s.

Retailleau, K., Belin de Chantemele, E. J., Chanoine, S., Guihot, A. L., Vessieres, E., Toutain, B., Faure, S., Bagi, Z., Loufrani, L., and Henrion, D. (2010). Reactive oxygen species and cyclooxygenase 2-derived thromboxane A2 reduce angiotensin II type 2 receptor vasorelaxation in diabetic rat resistance arteries. Hypertension 55, 339-344.

Roberts, C. K., Barnard, R. J., Sindhu, R. K., Jurczak, M., Ehdaie, A., and Vaziri, N.D. (2006). Oxidative stress and dysregulation of $\mathrm{NAD}(\mathrm{P}) \mathrm{H}$ oxidase and antioxidant enzymes in diet-induced metabolic syndrome. Metab. Clin. Exp. 55, 928-934.

Steinberg, H. O., Chaker, H., Leaming, R., Johnson, A., Brechtel, G., and Baron, A D. (1996). Obesity/insulin resistance is associated with endothelial dysfunction. Implications for the syndrome of insulin resistance. J. Clin. Invest. 97, 2601-2610.

Stepp, D. W., Pollock, D. M., and Frisbee, J. C. (2004). Low-flow vascular remodeling in the metabolic syndrome X. Am. J. Physiol. Heart Circ. Physiol. 286, H964-H970.

Subramanian, R., and MacLeod, K. M. (2003). Age-dependent changes in blood pressure and arterial reactivity in obese Zucker rats. Eur. J. Pharmacol. 477, 143-152.

Taddei, S., Virdis, A., Mattei, P., Ghiadoni, L., Gennari, A., Fasolo, C. B., Sudano, I., and Salvetti, A. (1995). Aging and endothelial function in normotensive subjects and patients with essential hypertension. Circulation 91, 1981-1987.

Wenzel, P., Schuhmacher, S., Kienhofer, J., Muller, J., Hortmann, M., Oelze, M. Schulz, E., Treiber, N., Kawamoto, T., Scharffetter-Kochanek, K., Munzel, T., Burkle, A., Bachschmid, M. M., and Daiber,A. (2008). Manganese superoxide dismutase and aldehyde dehydrogenase deficiency increase mitochondrial oxidative stress and aggravate agedependent vascular dysfunction. Cardiovasc. Res. 80, 280-289.

Wheeler-Jones, C. P. (2008). Regulation of endothelial prostacyclin synthesis by protease-activated receptors: mechanisms and significance. Pharmacol Rep 60, 109-118

Wu, D., Ren, Z., Pae, M., Guo, W., Cui, X., Merrill, A. H., and Meydani, S. N. (2007). Aging up-regulates expression of inflammatory mediators in mouse adipose tissue. J. Immunol. 179, 4829-4839.

Xiang, L., Dearman, J., Abram, S. R. Carter, C., and Hester, R. L. (2008). Insulin resistance and impaired functional vasodilation in obese Zucker rats. Am. J. Physiol. Heart Circ. Physiol. 294, H1658-H1666.

Xiang, L., Naik, J. S., Hodnett, B. L., and Hester, R. L. (2006). Altered arachidonic acid metabolism impairs functional vasodilation in metabolic syndrome. Am. J. Physiol. Regul. Integr. Comp. Physiol. 290, R134-R138.

Yan, C., Huang, A., Kaley, G., and Sun, D. (2007). Chronic high blood flow potentiates shear stress-induced release of $\mathrm{NO}$ in arteries of aged rats.
Am. J. Physiol. Heart Circ. Physiol. 293, H3105-H3110.

Young, E. J., Hill, M. A., Wiehler, W. B., Triggle, C. R., and Reid, J. J. (2008). Reduced EDHF responses and connexin activity in mesenteric arteries from the insulin-resistant obese Zucker rat. Diabetologia 51, 872-881.

Zanchi, A., Delacretaz, E., Taleb, V., Gaillard, R., Jeanrenaud, B., Brunner, H. R., and Waeber, B. (1995). Endothelial function of the mesenteric arteriole and mechanical behaviour of the carotid artery in rats with insulin resistance and hypercholesterolaemia. J. Hypertens. 13, 1463-1470.

Conflict of Interest Statement: The authors declare that the research was conducted in the absence of any commercial or financial relationships that could be construed as a potential conflict of interest.

Received: 26 May 2010; paper pending published: 09 June 2010; accepted: 11 October 2010; published online: 02 November 2010. Citation: Vessières E, Belin de Chantemèle EJ, Toutain B, Guihot A-L, Jardel A, Loufrani $L$ and Henrion D (2010) Cyclooxygenase-2 inhibition restored endothelium-mediated relaxation in old obese Zucker ratmesenteric arteries. Front. Physio. 1:145. doi: 10.3389/ fphys.2010.00145

This article was submitted to Frontiers in Vascular Physiology, a specialty of Frontiers in Physiology.

Copyright (C) 2010 Vessières, Belin de Chantemèle, Toutain, Guihot, Jardel Loufrani and Henrion. This is an openaccess article subject to an exclusive license agreement between the authors and the Frontiers Research Foundation, which permits unrestricted use, distribution, and reproduction in any medium, provided the original authors and source are credited. 